\title{
Las migraciones forzadas por la violencia: el caso de Colombia
}

\author{
M igrations forced by violence: the Colombian case
}

Gloria M arcela Gómez Builes ${ }^{1}$

Gilberto M auricio Astaiza Arias ${ }^{2}$

Maria Cecília de Souza M inayo ${ }^{3}$

\footnotetext{
${ }^{1}$ Facultad de O dontología, Universidad de Antioquia. Calle 64 N. 52-59. 2196702. Medellín, Colombia. magobu4@yahoo.es

${ }^{2}$ Universidad Sur

Colombiana.

${ }^{3}$ Centro Latino Americano de Estudos sobre Violência eSaúde, Fiocruz.
}

\begin{abstract}
The human migrations have been one of the motors in the history of humanity. During the twentieth century, internal forced displace ment has been an important component of the migration processesin theworld. Colombia, a paradigm for this phenomenon, is a country with more than three and a half million people displaced over the last 25 years by force of the violence resulting from an internal armed conflict. Besides the socio-demographic effects in the reconfiguration of the cities, this problem affects the human condition of the victims deteriorating their health and quality of life. This articleaims to show the general panorama of migrations forced by violence in the world and to analyze the peculiarities of this phenomenon in the Colombian case. We conclude that forced displacement is a serious violation of human rights producing a human drama by exposing the affected individuals and communities to vulnerability and a deep deterioration of their quality of life and health.
\end{abstract}

Key words Migration, Forced displacement, Violence
Resumo Las migraciones humanas han sido uno de los motores en la historia delas sociedades. Durante el siglo XX, el desplazamiento forzoso interno se ha constituido en un componente importantedelos procesos migratorios en el mundo. Colombia, uno de los casos paradigmáticos de este fenómeno, es un país con un acumulado de más de tres y medio millones de personas desplazadasforzadamentepor la violencia, en losúltimos 25 años desu historia, producto de un conflicto armado interno de origen sociopolítico. Además de los efectos sociodemográficos en la reconfiguración de las ciudades, esta problemática afecta la condición humana de cada una de las víctimas de este fenómeno, deteriorando la calidad de vida y la salud de estas personas. El presente artículo pretende, mediante una revisión sistemática, ofrecer un panorama general del fenómeno delas migraciones forzadas por la violencia en el mundo y analizar las particularidades de esta problemática en la experiencia colombiana. Deesta manera se afirma que el desplazamiento forzado es un drama humano que se concreta en la violación de los derechos humanos, y por lo tanto expone individuos y colectivos altamente fragilizados con un profundo deterioro de la calidad de vida y dela salud.

Palabras clave M igración, Desplazamiento forzado, Violencia 


\section{Introducción}

El desplazamiento forzado por la violencia es un componente de las migraciones humanas en el mundo del siglo XXI. Este se expresa como una crisis humanitaria que afecta la población de varios países, mediante la violación de los derechos humanos, generando un deterioro dela calidad de vida y salud de la población desplazada. De igual forma Colombia, presenta a 2005 aproximadamente 3.7 millones de personas que han sido desarraigadas, por un conflicto armado interno de origen sociopolítico, de larga duración, ocupando así el segundo lugar en el mundo después de Sudan en migraciones internas. El desplazamiento forzado por la violencia es un fenómeno sociodemográfico importante que determina los proce sos de urbanización de las ciudades. Allí los migrantes forzados buscan refugio, reconfigurando los espacios urbanos de manera caótica y desordenada, mediante recursos y factores sociales adversos y escasos para reconstruir sus vidasy redes sociales previamentedestruidas. Además los lugares de reasentamiento presentan condiciones de pobreza e indigencia, enmarcados dentro de procesos de exclusión. Estas condiciones de vida afectan negativamentea losindividuosy colectivos que allí se establecen, determinando los procesos de reproducción social y los problemas de salud. El presente artículo muestra mediante una revisión sistemática, un panorama general del fenómeno de las migraciones forzadas por la violencia en el mundo, analiza las particularidades de esta problemática en Colombia, y los efectos eimplicaciones de este, en la salud y calidad de vida en las personas en situación de desplazamiento forzado duranteel proceso dereasentamiento en la ciudad.

Las migraciones

en la historia de la humanidad

Desde los inicios de la humanidad, los seres humanos migran. Los éxodos y flujos no sólo han sido parte integrante de la historia, como también determinantes de la misma. El fenómeno de las migraciones es reconocido como un proceso esencial en la vida del ser humano sobre la tierra, que ha permitido generar diferentes desarrollos socio culturales y económicos. Desde la aparición del homo-sapiens en África hace aproximadamente 200 a 140 mil años, y con el inicio delas migraciones fuera de estecontinente hace $70 \mathrm{mil}$ años, se poblaron paulatina y progresivamente los diferentes hábitats de la tierra ${ }^{1}$.
Los desplazamientos intercontinentales de gran magnitud sólo comenzaron en el siglo XVI, con la expansión de Europa y los procesos de colonización. En los últimos dos siglos, las migraciones internacionales aumentaron, al canzando niveles sin precedentes ${ }^{2}$. Como todo hecho social, el fenómeno migratorio ha estado determinado por los procesos más generales de la sociedad. Para el momento histórico contemporáneo, la gl obalización y la internacionalización del modelo deproducción capitalista, de corteneoliberal, determinan las características de la dinámica migratoria mundial.

Podemos definir como migrante a toda persona que, por cualquier motivo, decide, mediante una elección tomada libremente, cambiar su lugar de residencia, ya sea de manera permanente o no. Es así como los procesos migratorios obedecen a decisiones concientementeplaneadas, buscando en la mayoría de los casos un mejor empleo, salarios mas altos, mejor educación para los hijos, motivos familiares (reunirse o acompañar a parientes, la formación de matrimonios) ${ }^{3}$. De esta manera, las migraciones están insertas en el sistema global, que se caracteriza por la apertura defronteras para el libremovimiento de capitales y mercancías, pero que, de manera contradictoria, restringe cada vez más la posibilidad de legalizar la situación de los migrantes económicos y laborales, e impone nuevas barreras para la entrada y movilidad de estas personas. Esta situación hace que la migración contemporánea exponga sujetos excluidos y cada vez más frágiles ante la explotación laboral. Además de la violación sistemática de los derechos humanos.

La Organización Internacional de M igraciones (OIM) considera el fenómeno de las migraciones humanas como una problemática de primer orden en la agenda internacional, en la medida que afecta tanto a los países receptores como a los de origen, debido al impacto demográfico y socio-económico que produce. Según las estadísticas, hay en el mundo para el 2005 aproximadamente 200 millones de migrantes internacionales, donde se excluyea los que han vivido fuera de su país por menos de un año. Desde 1970 al 2005 hay un aumento de 2,5 veces la cifra de migrantes internacionales; el 3\% de la población mundial está dentro de esta categoría. Los principales destinos de estas personas son: Europa con 56.1 millones y Estados Unidos con 35 millones de migrantes, que corresponde al $7.7 \%$ y el $20 \%$ de su población, respectivamente 4 .

Duranteel siglo XX y XXI paralelo a los procesos migratorios por motivos socio-económi- 
cos, la violencia, la guerra y los desastres naturales han producido millares de migrantes forzados en el mundo. Posteriormente a la caída del muro de Berlín o del bloque socialista, las gue rras internacionales redujeron su frecuencia, dejando paso a las confrontaciones de tipo étnico, religioso, y nacional, causantes de migraciones internas en los países en crisis ${ }^{5}$.

M igraciones forzadas por la violencia: un acercamiento a la situación mundial

Las migraciones internas por la violencia son un fenómeno social quesegún Naciones Unidas, afecta aproximadamente a 23,7 millones de personas en el mundo ${ }^{6}$. Este proceso es asumido por las poblaciones para prevenir las consecuencias del conflicto armado, especialmentela consecuencia irreversible de la muerte. Por lo tanto, la respuesta ante el peligro que representa la guerra se concreta en el abandono obligado del lugar de residencia habitual y de toda la cosmogonía que en él se había construido. La condición de migrante forzado tiene dos connotaciones dentro de la legislación internacional: De un lado están los refugiados, hombres y mujeres que se ven forzados a buscar protección por fuera desu país de origen, como consecuencia deun temor fundado de persecución por motivos de raza, religión o nacionalidad, por sus opiniones políticas, por su pertenencia a un grupo social, o por huir de las guerras y dela violencia en sus comunidades. La característica distintiva de la situación de refugiado es la salida del país de origen en búsqueda de protección. Esta situación implica que a nivel internacional se promueva la protección de estos sujetos bajo el mandato de la Organización de Naciones Unidas. Y a nivel nacional, que el Estado que le brinde la protección requerida respete sus derechos y no los retorne a su país de origen. De otro lado están las personas en situación de desplazamiento forzado interno, quienes han tenido que huir de su lugar de residencia y migrar dentro del territorio nacional, porque su vida se encuentra en riesgo como consecuencia del conflicto armado, situaciones de violencia, violaciones de los derechos humanos y del Derecho Internacional Humanitario. A nivel nacional, el Estado tiene la obligación de proteger a las personas que se encuentren bajo esta situación, brindar y promover soluciones duraderas. A nivel internacional la obligación se concreta en complementar las acciones de la respuesta estatal ante esta situación?.
De esta manera se puede decir que las causas que generan las migraciones forzadas son impuestas y no permiten ningún tipo de decisión planeada, ya que por lo general estos procesos se dan de un momento a otro, los autores irrumpen en la cotidianidad de las familias o comunidades enteras y no dan espera para la planeación de la vida a partir del acto violento, ya sean amenazas, homicidios, torturas, coacción ${ }^{8}, 0$ terror infundido a partir de "rumores" de experiencias cercanas.

Según el Centro de M onitoreo de Desplazamiento Interno - IDMC - a nivel mundial la mayor parte de los migrantes internos están expuestos a diferentes formas de violencia, al hambre, a enfermedades y sufren múltiples violaciones de los derechos humanos durante y posteriormente a su desplazamiento. De igual forma la atención integral a estas personas presenta grandes tropiezos. Se reporta que solo uno de cada dos refugiados recibe atención internacional y delos gobiernos ${ }^{6}$. Bajo la convención delos refugiados de 1951 y el protocolo de 1967, la comunidad internacional no es la responsable legal para proteger a los desplazados internos. La responsabilidad primaria de su atención recae en los gobiernos nacionales, quienes deben suministrar la seguridad y el bienestar para todos los desplazados ubicados en su territorio. Los problemas ocurren porque los gobiernos no están capacitados y organizados para atender a esta responsabilidad como está establecido en los principios rectores del desplazamiento interno de las Naciones Unidas.

De esta manera Bennet afirma que el desplazamiento interno no es un fenómeno nuevo. Cuando se redactaron la Carta de Naciones Unidas y las Convenciones sobre Refugiados, Ia proporción entre desplazados internos y refugiados era similar a la actual. Lo que ha cambiado es el número y la gravedad de las guerras internas y un crecimiento correlativo de la presencia y la cobertura otorgada a la migración forzosa por parte de la comunidad humanitaria internacional ${ }^{10}$. I gualmente, el creciente número de desplazados internos resulta del cambio en las prioridades del régimen internacional. La preocupación actual por limitar los flujos de refugiados y evitar el asentamiento a largo plazo ha tenido como resultado una política de cambio hacia la "internalización" del desplazamiento. Así, se hacen mayores esfuerzos para mantener a las personas en sus propios países, incluso si se encuentran lejos de sus lugares de origen ${ }^{10}$.

El desplazamiento forzado afecta a 50 países 
en los cinco continentes. Así, África es el más afectado con 12 millones de personas desplazadas en 20 países. Sudan, República Democrática del Congo y Uganda suman casi 9 millones de población desplazada. En la región del medio oriente este fenómeno es crítico, motivado esencialmente por el conflicto palestino-israelí y la guerra en Irak. Se estima que hay 2,1 millones de personas desplazadas, y casi 5 millones de refugiados de esta región. La mitad de las personas desplazadas las tiene I rak con casi 1.3 millones. Deesta manera, Asia presenta para finales de 2005 2,7 millones de personas bajo esta condición. Los conflictos internos activos más importantes son los de Filipinas, Burma, N epal e India que produjeron una cifra de 300,000 nuevos desplazados internos. Además países como Afganistán, Bangladesh Sri-Lanka y Uzbekistán continúan con sus conflictos internos crónicos, en los cuales los grupos rebeldes y los ejércitos nacionales violan sistemáticamente los derechos de la población civil, situada en medio de la confrontación. Europa es un continente que presenta pocos cambios en la problemática de las migraciones internas en los últimos años. En 2005 eran 2,8 millones de personas desplazadas internamente, unos 200.000 más que el 2004. En este continente la mitad de los afectados son refugiados oriundos dela Federación Rusa y los Balcanes, cuya intensidad disminuyó, con excepción de Armenia, $M$ acedonia y Croacia. En América Latina se calcula aproximadamente 3,8 millones de personas desplazadas por conflictos armados internos, la mayoría los aporta Colombia con una frecuencia de expulsión para el 2005 de aproximadamente 250.000 personas por año. A su vez, otros países como Guatemala, Perú y M éxico presentan migraciones internas que afectan especialmente a las poblaciones indígenas ${ }^{6}$.

En cuanto a los determinantes de estos procesos, se plantea que los principales agentes que causan el desplazamiento en el contexto internacional son los gobiernos nacionales, que a la luz de la ley internacional deberían proteger a los ciudadanos. Esto se da de manera directa 0 a través degrupos paramilitareso milicias quefuerzan a la población a dejar sus hogares. Los países como Sudan, Burma, Colombia N epal y Zimbabwe para el 2005 lo presentan de esta forma. Por otro lado, los grupos rebeldes han sido responsables de esta situación en casi el $40 \%$ de los casos mundiales en los que están incluidos Colombia, Burnadi, Nepal etc. También en este panorama del desplazamiento forzoso interno ha tenido impacto la política mundial de"lucha con- tra el terrorismo", debido a que ha motivado y justificado el accionar de los países que tienen conflictos internos para reprimir los diferentes movimientos sociales y políticos amparados en esta directriz internacional ${ }^{6}$.

El desplazamiento forzado por la violencia en la construcción dela historia colombiana

En Colombia los procesos migratorios, cuando se han presentado de forma masiva, han estado ligados a períodos históricos de violencia, además han estado motivados por razones económicas y laborales, cuando generaciones enteras partían de un territorio a otro con el propósito decolonizar tierras libres. Específicamente, estas migraciones forzadas por la violencia, en Colombia han presentado características singulares, que las diferencian de otros país que sufren desplazamientosinternos. En este sentido, sehan ilustrado tres elementos propios del caso colombiano en relación a este fenómeno: 1) la continuidad histórica del proceso de desplazamiento. Se afirma que contrario a lo que ocurre en muchos países donde los eventos de desplazamiento están asociados con hechos de guerra concretos, puntuales y específicos que se desarrollan en lapsos de tiempo relativamente cortos e intensivos, en Colombia el desplazamiento es un eje de pervivencia histórica que atraviesa la vida nacional desde la fundación dela república hasta el presente y que expone a lo largo del tiempo coyunturas agudas y períodos de relativa estabilidad poblacional ${ }^{11}$. Sin embargo, en las últimas décadas, esta situación ha tomado dimensiones de catástrofe humanitaria y se ha hecho visible como un fenómeno extensivo, diluido en el tiempo, recurrente y continuo, que combina éxodos al uviales familiares eindividuales; 2) la multipolaridad del conflicto armado y las dinámicas bélicas, ya que varios grupos armados participan en la contienda. Esta multipolaridad, tieneincidencia en el desplazamiento interno, en su natural eza, sus perfiles, sus especificidades, sus ritmos y sus tiempos; 3) la heterogeneidad y la ausencia deidentidades preexistentes entre los desplazados: estos forman un contingente heterogéneo, polivalente, con diferencias muy marcadas y muy pocas cosas en común, salvo su condición de víctimas de un conflicto armado de características muy particulare ${ }^{11}$.

Los procesos de violencia y expulsión se han expresado de manera particular en cada uno de los momentos históricos de la realidad colombiana. Así, se puede afirmar que la violencia ha 
sido un continuo en la forma de relacionarse de los colombianos expresándose en diferentes momentos, que han evolucionando en su magnitud, complejidad e intereses en juego, y dejando a su paso una profunda destrucción en los ámbitos social, económico, político; una grave crisis humanitaria expresada por el desplazamiento forzado de miles de colombianos que están moldeando sociodemográficamente el país ${ }^{12}$.

El primero de estos momentos históricos, tuvo lugar durante la guerra de los mil días de 1899 a 1902. Esta corresponde a la última y la más sangrienta confrontación de una serie de guerras civiles que azotaron el país durante la segunda partedel siglo XIX por desacuerdos entre las elites (centralistas y federalistas) que buscaban definir la configuración del Estado mediante la eliminación de sus oponentes. El desarraigo se producía al ser reclutados forzadamente campesinos y artesanos. No existen cifras ciertas sobre el número de personas desplazadas en esa época. Paralelo a lo anterior, cada grupo en confrontación expropió de sus tierras a los partidarios de sus oponentes, quienes de esta manera se vieron obligados a abrir frentes de colonización que fueron ampliando la frontera agrícola del país $s^{13}$.

El segundo momento ocurrió a mediados del siglo XX expresado por la confrontación partidista entre liberales y conservadores ${ }^{14}$. En 1948, con el asesinato del político liberal Jorge Eliécer Gaitán, se desata el alzamiento popular Ilamado el "bogotazo" queseextiendea todo el país. Tiene lugar la guerra civil no declarada conocida como "la violencia", que dura desde 1946 hasta 1958. Como resultado de ese periodo se produjo gran expansión de los latifundios, beneficiando a los grandes terratenientes, corporaciones ganaderas y agroindustriales. También el país se transformó socio-demográficamente, pasando del predominio rural a un país predominantemente urbano, principalmentepor el desplazamiento forzado de aproximadamente 2 millones de personas ${ }^{15}$. Posteriormente, como parte de la negociación política del conflicto interno, se vive en Colombia el periodo conocido como el "Frente Nacional", resultado del acuerdo pactado entre las clases dirigentes de ambos partidos políticos para alternarse el poder entre 1958 y 1974 . Durante este periodo se logra cierta estabilidad política y social en Colombia, pero se excluye dela participación política a otras fuerzas sociales ${ }^{12}$.

El tercer momento histórico del desplazamiento forzado en Colombia tuvo inicio en 1985 con la agudización del conflicto interno, con la disputa entre los actores armados mediante el control especialmente de las zonas rurales de Colombia ${ }^{16}$. Existeuna serie de características que diferencian el desplazamiento de los últimos 20 años de la historia colombiana con relación a las décadas anteriores. En palabras de Bello, las dé cadas de los ochenta y noventa representan un hito histórico en los procesos de despojo y expulsión, pues se caracterizan por una nueva agudización de la violencia, que en ocasiones no es más que la manifestación o continuidad de viejos conflictos y problemas no resuel tos. El desplazamiento forzado, es en esta época, la manifestación más clara de la permanencia histórica y la consolidación de un modelo de desarrollo excluyente ${ }^{17}$. I gualmente se ha planteado que en los últimos tiempos el desplazamiento forzado ha alcanzado dimensiones de crisis humanitaria.

En relación a este proceso, en la década de los 80, aparece en la escena colombiana el fenómeno del narcotráfico, que hará más complejo el escenario dela violencia política del país ${ }^{18}$. El problema "narco", según Franco, comprende la producción, tráfico y consumo de narcóticos. Inicialmente fue visto como un fenómeno periférico por la sociedad colombiana, luego con el tiempo fue infiltrando las diferentes esferas sociales, políticas, distorsionando el funcionamiento socio-económico del país y constituyéndoseen factor de violencia debido a que sus dineros, han servido para financiar la capacidad bélica de los grupos en confrontación, agravando la degradación del conflicto armado interno ${ }^{19}$.

\section{Contextos explicativos \\ del desplazamiento forzado}

Franco define contextos explicativos como un conjunto específico de condiciones y situaciones culturales, económicas y políticas en las cuales se hace socialmente posibley racionalmente comprensiblela presentación y el desarrollo de un fenómeno [...] No es solo el entorno situacional del acontecimiento, sino el entramado relacional que lo hace posibley entendible $e^{20}$. El mismo autor plantea que se habla de contexto económico, contexto político, cultural [...] Por la complejidad misma dela realidad, es frecuente quelos contextos no se encuentren puros, sino en diferentes y cambiantes composiciones. La explicación de eventos complejos se encuentra en la intersección de varios contextos ${ }^{19}$. En este sentido, es importante señalar que, como toda problemáticadela realidad social, el desplazamiento forzado es un fenómeno complejo que puede ser entendido desde varias lógicas. Este se confi- 
gura desde dos grandes dimensiones: de un lado, como expresión de procesos generales y estructurales de una sociedad determinada por la globalización del modelo de producción capitalista, que impone una lógica particular, pero homoge neizante, para comprender la organización social y las relaciones quese dan al interior de esta. Bello lo reconocecuando plantea que"en Colombia los procesos violentos de despojo y expulsión parecieran ser el mecanismo deadecuación a las necesidades deproducción y acumulación queel capitalismo impone"17. Deotro lado, el desplazamiento se configura desde la historia colombiana y su manera particular de construir la sociedad, en la cual, la guerra, la violencia, sus estrategias y efectos, han sido elementos característicos y estructurales de su cultura y política.

De esta manera Suárez habla de una circularidad viciosa entre la configuración y las características del Estado colombiano, la persistencia de las causas estructurales de los diversos conflictos sociales, políticos, económicos y culturales y, la migración forzada en Colombia. La debilidad estructural del Estado incrementa las causas estructurales del conflicto y de la crisis humanitaria asociada al desplazamiento forzado, y, a su vez estas causas estructurales aceleran el proceso de desplazamiento forzado y sus efectos ${ }^{21}$.

Cuando se habla de desplazamiento forzado en Colombia se encuentran dos perspectivas en relación a su explicación. Para unos autores, este fenómeno es una consecuencia directa del conflicto armado, de la confrontación político militar entre dos o más actores de la guerra, donde la población que habita los territorios en los cuales se desarrollan los combates, no encuentra más opción que huir para no quedar en medio del fuego cruzado. Para otros, el desplazamiento se ha configurado como la principal estrategia de guerra de los actores armados, en su disputa territorial, para establecer y consolidar su soberanía en territorios estratégicos y económicamente explotables. Desde esta última perspectiva, la Escuela Latino Americana de Cooperación y Desarrollo plantea que la tierra ocupa un lugar preponderante en el origen y desarrollo del conflicto armado colombiano, ya sea como activo productivo o como escenario estratégico de acuerdo a los objetivos militares por los cuales los actores armados puedan buscar el control del territorio. [...] Esta estrategia, tieneuna doblefinalidad: por una parte, desde el punto de vista militar, crear corredores de seguridad que no sólo les permita contar con espacios de avanzada y retirada, sino también el control sobre la población. Por otra, correspondeal interés económico de buscar fuentes de financiación relacionadas con el desarrollo de megaproyectos productivos, extractivos y de infraestructura ${ }^{22}$. Así se plantea que cuando los campesinos huyen, los terratenientes locales y losinversores nacionaleso multinacionales pueden apropiarseo adquirir por un costo mínimo la tierra abandonada ${ }^{23}$.

En relación a esta discusión, Pérez insiste en analizar el fenómeno no como un simple efecto de las acciones armadas, sino como un problema de orden nacional que obedece a causas de tipo estructural, porque el desplazamiento forzado está atravesado por múlti ples y complejos problemas sociales que tienen efectos sobre las estructuras de tenencia de la tierra, las estrategias de acumulación de la riqueza y la especulación con terrenos productivos o con alto valor real o potencial, entre otros ${ }^{24}$. Por lo tanto se identifica el desplazamiento como una estrategia de guerra de los actores armados, quetiene referentes económicos, políticos, sociales y militares.

\section{Actores \\ del conflicto socio-político colombiano}

Zuluaga afirma que "la guerra colombiana es profundamente regionalizada, y presenta un desarrollo desigual"25. A su vez, Bello plantea queel mapa de desplazamiento forzado en Colombia, señala claramente que las zonas de donde más se expulsan colombianos demanera violenta, son aque Ilas que revierten valor estratégico especialmente en las que se ubicaran megaproyectos. También señala como estratégicas las zonas valoradas como corredores (tránsito de armas, paso de ejércitos, circulación de ilícitos, etc.); zonas para el repliegue de los grupos armados y las aledañasa los centros de decisión política. Los territorios ricos en recursos minerales y energéticos, son escenarios que igualmenteseconvierten en zonas en disputa. Además, dentro de las estrategias de lucha antisubversiva de militares y paramilitares, las zonas en donde tradicionalmente se ubicó la guerrilla con sus respectivas 'bases sociales deapoyo' ( muchas deellas zonas estratégicas por los aspectos mencionadosanteriormente) han sido objeto de confrontaciones armadas, y dramáticamente de acciones atroces contra la población civil, que es señalada como simpatizante, colaboradora o 'guerrilleros vestidos de civil'. En este sentido se afirma que los territorios son despoblados y repoblados al antojo de los actores armados ${ }^{17}$.

En estesentido, es importanteanotar que, existen diferencias y particularidades de cada uno de 
los actores armados en confrontación: las guerriIlas contra-estatales, los paramilitares 0 actores paraestatales y las fuerzas militares del Estado. Dentro del losactores contra-estatales, seencuentran aún activas, de un lado, las Fuerzas Armadas Revolucionarias de Colombia (FARC) que nacieron como resistencia del movimiento campesino contra la violencia del gobierno en 1964, y con un origen ligado a las luchas por la tierra y la construcción de la reforma agraria; de otro lado, el Ejercito de Liberación Nacional (ELN), que se origina dentro de un grupo de estudiantes, dirigentes sindicales y profesionales quienes deciden crear una organización político-militar inspirada en la ideología marxista y cristiana para transformar la sociedad y construir el socialismo ${ }^{25}$. En la década de los 80 y casi paralelamentecon el fenómeno del narcotráfico, surgen las fuerzas paramilitares, como otro actor armado del conflicto colombiano. Estos grupos fueron conformados y financiados por particulares (latifundistas, narcotraficantes y ganaderos) para contrarrestar la extorsión y los secuestros de la guerrilla, y proteger sus patrimonios. Se ha considerado también al paramilitarismo como un componente de la política contrainsurgente del Estado, que se ampara en grupos armados anónimos, para realizar actividades anti-guerrilleras con el apoyo directo o velado de las Fuerzas Armadas. En ocasiones los grupos paramilitares actúan en territorios dondeel Estado no ha hecho presencia. Estefenómeno ha tenido un crecimiento importante en lo militar y político, agudizando más la degradación el conflicto armado y convirtiéndose en los mayores causantes de los desplazamientos forzados mediante las masacres y las amenazas de muerte a las poblaciones rurales ${ }^{26}$. Se afirma que el paramilitarismo es el mecanismo que el Estado colombiano, reinterpretando experiencias de otros países en los mismos manuales dela Escuela delas Américas, ha logrado situar como el más "eficaz" para su lucha contrainsurgente o mejor en su confrontación con todo lo democrático, lo alternativo, lo disidentere ${ }^{27}$. En cuanto al papel del Estado como actor del conflicto, Correa apunta queéste desdeun principio, ha tenido la estrategia de evasión de sus responsabilidades estatales para erigirsecomo una víctima más de la violencia; además que la sofisticación del modelo de represión y control que pasa de la tortura a la desaparición forzosa, del asesinato selectivo al desplazamiento forzado a través de las diversas formas de paraestado y de guerra integral, son la clara expresión de la participación por inercia del Estado en la violenciay el desplazamiento en Colombia ${ }^{27}$.
En relación a los hechos que motivan los desplazamientos, cabe anotar que según la Consultoria para los Derechos H umanos y el desplazamiento - Codhes -, las amenazas constituyen el $64 \%$ de las motivaciones para el desplazamiento, seguidas por asesinatos (14\%), torturas ( $1 \%$ ) y "otros" (15\%), entrelos queseincluye "el miedo" , la "persecución" "intento de secuestro" y el "boleteo" ${ }^{28}$. Además, en cuanto a la participación de los actores armados en los desplazamientos, los paramilitares muestran un incremento como agente desplazador del $21 \%$ a mediados de los ochenta al $42 \%$ a finales de los noventa, le siguen los grupos guerrilleros con el 32\%, con un decremento para el mismo periodo al $29 \%$ y las fuerzas armadas estatales del $20 \%$ a un $15 \%$. En el $43.1 \%$ de los casos de desplazamiento participan dos actores armados y en el resto de los casos solo participa uno ${ }^{29}$.

\section{La población desplazada, sus condiciones de vida y salud}

En Colombia se estima que entre 1985 y 2005 existeun acumulado de 3.720 .428 personas desplazadas al interior del país $5^{30}$, ocupando el segundo lugar a nivel mundial después de Sudán ${ }^{31}$. Además, Colombia es el escenario del conflicto armado interno de mayor duración en Latinoamérica ${ }^{23}$. Estos datos evidencian la magnitud de esta situación, que genera uno de los fenómenos sociales y humanitarios más complejos y críticos de la realidad colombiana, con la fragmentación de las estructuras sociales de varias regiones y produciendo el reordenamiento social y demográfico del país, con el desalojo rápido de la población de los territorios, con cambios en la tenencia de la tierra, expresados en una contrarreforma agraria, cuyos efectos se expresan en la calidad de vida de los campesinos desplazados, y en el resto de la población colombiana ${ }^{27}$.

En relación a las estadísticas, la frecuencia anual de desplazados ha tenido una tendencia al aumento desde la exacerbación conflicto a partir de 1985, con un pico máximo de 433.453 personas en el 2002. En el 2003 seobserva un descenso notorio de casos, casi la mitad del año anterior (207.607), situación que se puede explicar por el cambio de la modalidad expulsiva a la de confinamiento, o por los procesos de resistencia civil de comunidades al negarse a desplazarse, como también al proceso de desmovilización de los paramilitares en negociaciones de paz con el gobierno, y por último, al subregistro en los siste- 
mas de monitore $0^{32}$. De otro lado, se estima que en Colombia, a cada hora son desplazados dos hogares por la violencia. Es decir, que en los últimos veinte años han sido desplazados por la violencia el $7.8 \%$ de la población, en promedio 474 personas o 95 hogares por día, quienes llegan a zonas marginales urbanas ${ }^{33}$. Franco apunta que solo en el 2005 fueron desplazadas 310.000 personas al interior del país ${ }^{34}$. De igual forma, para finales de los años noventa, 11.700 colombianos buscaron refugio y protección en países vecinos como Panamá, Venezuela y Ecuador, y para el 2003 fue de un total aproximado de 13 mil personas que oficialmente buscaron refugio en países como Ecuador (10.086) y Venezuela (2.386) ${ }^{35}$.

En cuanto a las características de la población, se reporta que los desplazados en su gran mayoría $(70 \%)$ son campesinos y personas pertenecientes a comunidades étnicas, afro-colombianas eindígenas. Las mujeres, niños y niñas, indígenas y negros constituyen el grupo más afectado por el desplazamiento forzado. El 55\% corresponde a menores de 18 años, que se reparte en $12.72 \%$ menores de 5 años, el $19.78 \%$ está entre 5 y 10 años, el $12.78 \%$ entre 11 y 14 años yel $9.03 \%$ tiene entre 15 y 18 años $^{32}$. Como se puede observar este fenómeno afecta principalmente a los campesinos, a las poblaciones empobrecidas y excluidas históricamente como las minorías étnicas. Sin embargo, Naranjo ${ }^{36}$ plantea que no es en razón desu pertenencia cultural quese les persigue sino por las mismas razones o sin razones que se obliga a huir a blancos o mestizos. Los desplazados en Colombia no constituyen una etnia, una nacionalidad, una comunidad religiosa, un partido, una colectividad política o ideológica y no están definidos por alguna identidad preexistente; por el contrario, el único rasgo que parecen tener en común es su condición de víctimas del conflicto armado; su situación de exclusión y desarraigo, la ausencia de reconocimiento y las heridas morales producidas por el despojo y el olvido. Dada la naturaleza del conflicto armado, cual quier persona en cualquier lugar del territorio nacional puede ser una víctima potencial.

Además de la discusión alrededor de la población desplazada, es importante reiterar que el desplazamiento forzoso es una grave violación a los derechos humanos que produce un profundo deterioro de la calidad de vida de los desplazados. Estas personas expresan, por esta razón, incapacidad para satisfacer sus necesidades básicas, fragilizando su existencia humana. Eventos tales como la expropiación de sus bienes (vivienda y tierra), de las fuentes de trabajo, pérdida del acceso a las propiedades comunales, conducen a la desarticulación social con pérdida del capital social por la destrucción de las identidades individuales y grupales y de los lazos comunitarios, una elevada fragmentación familiar y grupal por las pérdidas de al gunos de sus miembros ${ }^{37}$. Estos hechos no les permiten afrontar de forma adecuada la supervivencia en los lugares de reasentamiento, donde se suma el abandono del Estado, la hostilidad por parte de las comunidades receptoras y las precarias condiciones de vida.

Particularmente el desplazamiento tiene un grave impacto en la salud. Como lo expresa el estudio sobre Salud y desplazamiento forzado realizado por la Organización Panamericana de la Salud y la Universidad de Antioquia ${ }^{38}$, estas poblaciones expresan negativas condiciones de vida y salud en los sitios de recepción: en relación a las condiciones sanitarias se reporta que las viviendas son construidas con materiales demala calidad, desechables como cartón y madera y pisos en tierra. Se presenta una inadecuada disposición de las basuras, lo que se concreta en malas condiciones sanitarias con una alta infestación por plagas en las viviendas. Además, la cobertura en el acceso a los servicios públicos domiciliaros es baja; el manejo de los residuos sólidos y líquidos presenta una infraestructura deficiente con la mitad de las viviendas sin conexión al alcantarillado.

Este mismo estudio encontró que en los hogares de los desplazados hay 1.7 veces más hacinamiento que los hogares de las poblaciones receptoras. Esta es una de las condiciones que generan un mayor riesgo de exposición a enfermedades infecto-contagiosas de tipo respiratorio e hídrico como las infecciones respiratorias agudas y las enfermedades diarreicas agudas. Además, se evaluó en esta población la morbilidad sentida, donde se encontró en el 50 por ciento de los participantes, una percepción de haber estado enfermo 15 días antes de participar en el estudio. De igual forma, los padres del 70 por ciento de los niños y niñas menores de un año consideraron que sus hijos estuvieron enfermos en el mismo periodo. La sintomatología expresada estuvo re lacionada con enfermedades infectocontagiosas, principalmente, infecciones respiratorias agudas y de enfermedades diarreicas agudas.

Por otro lado se evaluó la afiliación al sistema de salud de los desplazados y los principales hall lazgos evidencian la existencia de problema en el acceso, económico y geográfico por parte de las instituciones responsables de brindar los servicios de atención para la salud. Además, se ha 
planteado que 2 de cada 10 desplazados no poseen ningún documento deidentidad, lo que afecta la subjectividad ademas de ser requisito para acceder a la prestación de los servicios. Por lo tanto, la dificultad para ser reconocidos como personas en situación de desplazamiento, el alto costo de las consultas medicas y los medicamentos, además dela discriminación institucional, hacen que al rededor de $30 \%$ de la población desplazada esté privada de los servicios de salud ${ }^{39}$.

Estos son algunos datos que nos permiten un acercamiento descriptivo y general para evidenciar la vulnerabilidad de estas personas, a nivel individual y colectivo, constituyén dose en grupos prioritarios para las acciones en salud y la atención del Estado. A este respecto la Corte Constitucional de Colombia, declaró en la sentencia T-025 de 2004, que la situación de la población desplazada en Colombia se había configurado en un "estado de cosas inconstitucional", en la medida en que la respuesta estatal no daba respuesta a la dimensión del problema, no operaba como un sistema integral, y entre tanto las condiciones de vida de la población afectada se veían cada vez más precarizadas. I gual mente en 2006 la Corte conceptuó que "no se ha demostrado que se haya superado el estado de cosas inconstitucional declarado en la sentencia T-025 de2004, ni que seestéavanzando en forma acelerada y sostenida hacia su superación", advirtiendo la persistencia de falencias en la respuesta gubernamental relacionadas con la persistencia del subregistro, de las inconsistencias en la asignación presupuestal, en la ausencia de programas de atención especiales para esta población, conformea su condición de víctimas de violacionesa derechos humanos; la desprotección de los indígenas y afrocolombianos desplazados y en la falta de seguridad para los retornos y de garantías para una vida digna ${ }^{40}$.

El no retorno:

la reconfiguración de las ciudades en el encuentro de nuevos y antiguos pobladores

A partir del instante en que se asume la huida como la respuesta ante los elementos de fuerza que obligan al desplazamiento, cada una de estas personas, en compañía de su grupo familiar o de manera individual, se ve en la tarea de definir el lugar de destino. Así, las ciudades se constituyen en los principales centros de recepción delas personas que huyen de las consecuencias de la guerra. Estos espacios"ofrecen la posibilidad de mi- metizar la identidad en medio de la diversidad, mayores oportunidades de supervivencia" ${ }^{41}$. De igual forma, se plantea quela alternativa de refugio político es exclusiva para personalidades individuales que por su función pública o reconocimiento social logran apoyo del gobierno o de los organismos internacionales de derechos humano ${ }^{42}$. I gualmente, la posibilidad de traspasar las fronteras del país se convierte en una opción para aquellos individuos o familias de las clases socioeconómicas con mayor poder adquisitivo lo que, para el caso de Colombia, representa una minoría. Por lo tanto las multitudes de desplazados peregrinan entre las fronteras internas buscando protección y condiciones para reconstruir la vida.

Generalmente, son las zonas dela periferia de la ciudad, las laderas de las montañas, reconocidas como zonas de alto riesgo geológico, con carencia en los servicios sociales básicos, y con altos niveles de desnutrición, desempleo y violencia, los lugares donde se insertan los centenares de hogares, que al no contar con la capacidad económica mínima para proveerse una vivienda digna, encuentran en estos territorios la única opción paraestablecer una residencia permanente.

Como se desprende de la situación planteada en esteartículo, los desplazados se constituyen en un colectivo, que marcado por las historias particulares, expone una serie de necesidades sociales a partir del evento violento que los desterró. $R e-$ crea una situación donde es perentorio encontrar oportunidades de vida en la ciudad, ya que no existen condiciones reales para un retorno hacia los lugares deprocedencia por la permanencia del conflicto armado y los dispositivos que un día provocaron el desplazamiento forzado.

Deesta manera es posible dimensionar el desplazamiento forzado como un proceso dialéctico, que expone una clara contradicción entre, de un lado, las situaciones de ruptura, dispersión y desarraigo generadas a partir de la situación de desplazamiento. De otro lado, la convergencia y el encuentro de diversos mundos culturales ehistóricos, que se da en los espacios de asentamiento como consecuencia de la interacción y convivencia de la población victima de esta situación con los habitantes históricos de las ciudades. Por lo tanto, seconfigura un nuevo orden de relaciones a partir de los procesos de desplazamiento forzado. Y de esta forma se reconfiguran los procesos de urbanización y la construcción de las ciudades, determinadas por los procesos de migración forzada. 


\section{Conclusión}

Después de hacer un recorrido general por la situación de las migraciones forzadas en el mundo, se podría afirmar que para acercarsea la comprensión de fenómenos sociales como el desplazamiento es necesario hacer una lectura crítica y compleja de aspectos generales y estructurales de las sociedades, desde una perspectiva histórica. Pero además es necesario reconocer las características particulares y los el ementos de coyuntura que determinan ese devenir histórico en cada uno de los contextos de la vida nacional de cada país, que desencadenan procesos dinámicos de construcción y deconstrucción de la vida y la sociedad, de manera diferenciada.

En este sentido, encontramos experiencias de países que, por un lado, son expulsores de multitudes de personas que traspasan las fronteras internacionalmente reconocidas; de otro lado, son receptores de hombres y mujeres que se refugian en su territorio en busca de protección; y por otro lado, países que tienen esa doble connotación: expulsor y receptor de su propia población, dentro de los límites del territorio nacional, como es el caso de aquellos gol peados por la problemática de los desplazamientos forzados internos.

Como ya se mencionó, además de las estadísticas, la realidad de cada país se diferencia por la manera como cada uno ha construido su historia, dentro de la dinámica general global. Así el caso colombiano, que fue resaltado en el presente artículo, se constituye en una experiencia particular, caracterizada por procesos violentos de despojo y desarraigo que han atravesado la historia nacional con algunos periodos de mayor expresión y complejidad; la diversi dad de actores eintereses que determinan la guerra interna y sus efectos; y la población víctima de estos procesos, constituida por millares de hombres y mujeres sin ninguna identidad colectiva previa. Por el contrario, comunidades heterogéneas, familias, individuos que han sido expulsados de sus tierras, de su residencia habitual, por encontrarse ubicados en lugares importantes para los actores de la guerra, quienes en su disputa, utilizan el desplazamiento forzado como su principal estrategia.

De esta manera, como se ya se analizó, la población huye principalmente por defender la vida, amenazada por las situaciones de violencia y horror en el entorno más cercano. Se parte como resistencia a la muerte y como expresión del derecho a vivir, pero en ese destierro impuesto por intereses y fuerzas externas a la voluntad de cada una de estas personas, se abandona el mundo concreto y simbólico que se había construido hasta entonces, relacionado en la mayoría de los casos con el acceso y disfrute de la tierra, o de otros medios de producción. Por lo tanto, desde el momento en que se asume el desplazamiento como única respuesta ante el contexto dehostilidad y violencia, estas personas se ven vulneradas en su derecho al trabajo, a la familia, a un nivel de vida digna, a la alimentación, a la salud y a la vivienda, principalmente. Además en el contexto de reasentamiento, generalmente urbano para el caso de Colombia, aparecen nuevas amenazas representadas por las precarias condiciones de vida que encuentran en la ciudad y por las pocas oportunidades que existen para comenzar de nuevo y restituir los derechos vulnerados a partir del desplazamiento.

A pesar de ser Colombia un Estado constitucional mente definido y reconocido como social y de derecho, de haber suscrito los diferentes pactosinternacionales delos Derechos H umanos, no existeuna garantía real para el ejercicio de los mismos. Esta situación se evidencia claramentecon la población desplazada. Como ya lo han afirmado diferentesautores, en lasituación de desplazamiento forzado se sintetiza la violación sistemática de los derechos humanos, tanto los civiles y políticos, como los sociales, económicos y culturales. D'Elia ha planteado que "los derechos son valores indiscutibles o no negociables que se construyen o se conquistan socialmente, convirtiendo necesidades en aspiraciones y estas en obligaciones cuando se traducen en normas y leyes" ${ }^{\prime 3}$.

De esta manera, un acercamiento a un caso particular, a un micro-contexto, como el colombiano, permite, en primer lugar, describir y comprender las características y dinámicas propias de un sistema local; en segundo lugar, leer, desde una experiencia particular, la expresión de los procesos generales globales. Por lo tanto, sin pretender generalizar, se podría afirmar quesi bien la situación de Colombia presenta singularidades, también pone en evidencia la realidad que enfrenta cotidianamente la mayoría de las familias y personas que han sido desplazadas forzadamente y queviven en condiciones de pobreza económicae indigencia, como producto de procesos históricos, sociales, económicos y políticos que se han caracterizado por ser inequitativos y excluyentes.

Finalmente, para la salud colectiva, como campo de conocimiento y de acción, que reconoce la historicidad de los procesos sociales, la naturaleza política de los hechos sanitarios y sus prácticas, y la necesidad de abordajes teóricos y metodológicos transdiciplinares para interpre- 
tar, comprender y explicar los problemas de salud, las migraciones forzadas y sus efectos en la vida de las poblaciones, se constituyen en objeto legítimo de estudio eintervención, ya quela calidad de vida y la salud se ven negativamente afectadas por estos procesos de violencia y despojo. Los lugares de reasentamiento en el contexto ur-

\section{Colaboradores}

GM Gómez y GM Astaiza participaron en la concepción teórica, elaboración y redacción del artículo. MC de Souza Minayo participó en la concepción teórica y revisión crítica del artículo.

\section{Referencias}

1. M aca-M eyer N, González AM, Larruga JM, Flores C, Cabrera VM . Linajes mayores del genoma mitocondrial trazan antiguas expansiones humanas. $\mathrm{Ge}$ netics 2001, 2:13.

2. Fundo das $\mathrm{N}$ ações Unidas Para a População. 0 bom, o mau o promissor. M igrações no século XXI Situação da população mundial 2006. Passagem para a esperança: mulheres e migrações internacionais. Brasília: PNUD; 2006. p. 5.

3. Velasco JR. Demografía social y salud pública. Cali: Facultad de Salud, Universidad del Valle; 1990. p. 78.

4. International Organization for Migration (IOM). World migration report 2005: Cost and benefits of international migration. World Migration Report Series, volume 3. Geneve: IOM. [Documento en Internet]. [Consultado el 10 de noviembre de 2006]. Disponible en: http://www.iom.int/jahia/Jahia/cache/ bypass/pid/8?entryld=932. pdf

5. Adelman $\mathrm{H}$. From refugees to forced migration: The UNHCR and human security. International Migration Review 2001; 35(1):7-32.

6. Internal Displacement M onitoring Centre (ICMC). Norwegian Refugee Council. Internal Displacement: Global Overview of Trends and developments in 2005. Geneva: ICM C; 2006.

7. Rueda Bedoya R. Desarrollo urbano y desplazamiento forzado por la violencia sociopolítica en Colombia. En: Consultoria para los derechos humanos y el desplazamiento -Codhes. Desplazamiento forzado interno en Colombia, Paz y Desarrollo, Me morias Seminario Internacional. Bogotá: Editorial Kimpres; 2000. p. 123-147.

8. Secretariado Nacional de Pastoral Social Sección de M ovilidad Humana. RUT sobre desplazamiento forzado en Colombia. Boletín trimestral 2002; 12:9.

9. Teitelbaum M. Inmigration, refugees, and foreign policy. International organization 1984; 38 (3):429-450. bano están marcados por la pobreza, la precariedad, la informalidad y la exclusión. Además el abandono del Estado y sus instituciones expone colectivos humanos frágiles y vulnerables con necesidades sociales específicas que requieren acciones intersectoriales para transformar la realidad y construir condiciones de vida dignas.
10. Bennet J. La migración forzada dentro de las fronteras nacionales: el orden del día de los desplazados internos. Revista M igraciones Forzadas 1998; 1):4.

11. Naranjo GE, Nieto GP, Jaramillo AM, González A. Desplazamiento forzado en Antioquia 1985-1998. M 0dulo 0: aproximaciones teóricas y metodológicas. Bogotá: Secretariado Nacional de Pastoral Social Sección de Movilidad Humana/ Universidad de Antioquia - Instituto de Estudios Políticos; 2001.

12. Oquist P. Violencia, conflicto, y política en Colombia. Bogotá: Banco Popular Instituto de Estudios CoIombianos; 1978.

13. Sánchez $G$, Peñaranda $R$, compiladores. Pasado y presente de la violencia en Colombia. Bogotá: Fondo Editorial CEREC; 1991.

14. Boot JA. Rural violence in Colombia: 1948-1963. The Western Political Quarterly 1974; 27(4):567-679.

15. Flores CE. Las transformaciones sociodemográficas en Colombia, durante el siglo XX. Bogotá: Banco de Ia República/Tercer Mundo Editores; 2000.

16. Pearce J. Colombia dentro del laberinto. Bogotá: Altesnir Ediciones; 1992.

17. Bello MN. El desplazamiento forzado en Colombia: Acumulación de capital y exclusión social. En: Bello M M, compiladora. Desplazamiento forzado. Dinámicas de guerra, exclusión y desarraigo. Bogotá: Alto Comisionado de $\mathrm{N}$ aciones U nidas para los Refugiados; 2004.

18. M anosalva C, Bedoya J. Conflicto armado y salud en Colombia 1997-2002: Balance de fuentes secundarias. Bogota: Universidad Nacional de Colombia Facultad de Enfermería; 2003.

19. Franco S. El quinto: no matar. Contextos explicativos de la violencia en Colombia. Bogotá: Tercer Mundo Editores; 1999.

20. Franco $\mathrm{S}$. Momento y contexto de la violencia en Colombia. Rev. Cubana Salud Pública 2003; 29(1):1836. 
21. Suárez HD. Desplazamiento Forzado, crisis humanitaria y de derechos humanos y Estado débil. En: Bello M N , compiladora. Desplazamiento forzado. Dinámicas de guerra, exclusión y desarraigo. Bogotá: Alto Comisionado de Naciones Unidas para los Refugiados/Universidad Nacional de Colombia; 2004.

22. Escuela Latinoamericana de Cooperación y Desarrollo. Efectos económicos del desplazamiento forzado en Colombia: departamentos de Antioquia, Bolívar y Valle del Cauca 1997-2004. Cartagena: Universidad de Cartagena; 2005.

23. Loughna S. Colombia: la búsqueda de la paz en medio del conflicto. Revista M igraciones Forzadas 1998; 1:16-15.

24. Pérez Murcia LE. Factores asociados al desplazamiento forzado en Colombia. En: Bello, M N, compiladora. Desplazamiento forzado. Dinámicas de gue rra, exclusión y desarraigo. Bogotá: Alto Comisionado de Naciones Unidas para los Refugiados/U niversidad Nacional de Colombia; 2004.

25. Zuluaga Nieto J. La guerra interna y el desplazamiento forzado. En: Bello MN, compiladora. Desplazamiento forzado. Dinámicas de guerra, exclusión y desarraigo. Bogotá: Alto Comisionado de Naciones Unidas para los Refugiados/U niversidad $\mathrm{Na}$ cional de Colombia; 2004.

26. Páramo CG. Civilización y barbarie en el proyecto paramilitar. En: Cubides F, Domýn C, compiladores. Desplazados, migraciones internas y reestructuraciones territoriales. Bogotá: Facultad de Ciencias Humanas, Universidad Nacional; 1999.

27. Correa C, Rueda D. La barbarie irracional de la gue rra: Efectos psicosociales y culturales del desplazamiento. Bogotá: Universidad Nacional del Colombia; 2000

28. Consultoria para los Derechos Humanos y el desplazamiento (Codhes). Boletín n. 20. Bogotá: mayo 9 de 2002. [Documento de internet]. [Consultado el 16 de noviembre de 2004]. Disponible en: http://www.codhes.org

29. Conferencia Episcopal Colombiana. Boletín trimestral sobre el desplazamiento forzado en Colombia (septiembrediciembre). Bogotá: Editorial Kimpres; 1995.

30. Consultoria para los derechos humanos y el desplazamiento (Codhes). [Documento de internet]. [Consultado el 20 de noviembre de 2006]. Disponible en: http://www.codhes.org/estadisticas/

31. Global Internally Displaced Person Project. Estimaciones del número de desplazados internos a nivel internacional (2001-2002). En: Palacio S, Sabatier $\mathrm{C}$. Impacto psicológico de la violencia política en los jóvenes y sus familias: características de salud mental y redes sociales en familias desplazadas y pobres del Atlántico, Barranquilla: Ediciones Uninorte; 2002

32. Consultoria para los Derechos Humanos y el desplazamiento (Codhes). Boletín Codhes informa. (Boletín periódico sobre desplazamiento forzado). [Documento de internet]. [consultado $2006 \mathrm{~N} \mathrm{ov}$ 19]. Disponible en: http://www.codhes.org

33. Codhes/UNICEF. Un país que huye. Desplazamiento y violencia en una nación fragmentada. Bogotá: Gente Nueva; 2003.
34. Franco S, Suarez CM, Naranjo CB, Báez LC, Rozo $P$. The effects of the armed conflict on the life and health in Colombia. Cienc Saude Colet 2006, 11(2):349-361.

35. Consultoria para los Derechos Humanos y el desplazamiento (Codhes). Desplazados: ni seguridad, ni democracia. Boletín Codhes informa [periodico en Internet]. Abril 2004. [consultado 2005 Jun 15]. Disponible en: http://www.codhes.org

36. Naranjo G. El desplazamiento forzado en Colombia. Reinvención de la identidad e implicaciones en las culturas locales y nacional. Scripta N ova, revista electrónica de Geografía y Ciencias Sociales 2001; 94(1):6-11.

37. Malagón R. Salud y calidad de vida un enfoque innovador: repensar las relaciones entre calidad de vida y salud. En: Franco S. editor. La salud pública hoy: enfoques y dilemas contemporáneos en Salud Pública. Bogotá: Universidad Nacional de Colombia; 2003. p. 209

38. Organización Panamericana de la Salud/U niversidad de Antioquia. Serie salud y desplazamiento en Colombia: Comparación de la situación de salud, entre la población en situación de desplazamiento y receptora, en seis ciudades. 2002-2003. M odulo 1. Medellín: Organización Panamericana de la Salud/ Universidad de Antioquia; 2005.

39. Organización Panamericana de la Salud. Situación de salud en Colombia. Indicadores básicos 2004. Bogotá: Organización Panamericana de la Salud; 2005.

40. Gutierrez A. Proteger a las víctimas del desplazamiento: el primer deber del Alto Comisionado de $\mathrm{N}$ aciones Unidas para los Refugiados en Colombia. Informe de Organizaciones no gubernamentales presentado al Alto Comisionado de Naciones Unidas para los Refugiados. Consultoria para los derechos humanos y el desplazamiento (Codhes). [Documento en internet]. [consultado $2007 \mathrm{M}$ ar 24]. Disponible en: http//www.codhes.org

41. Consultoria para los derechos humanos y el desplazamiento (Codhes). Crisis humanitaria y catástrofe social. Boletín n. 31. En: Codhes/UNICEF. Un país que huye. Desplazamiento y violencia en una nación fragmentada. Bogotá: Gente Nueva; 2003.

42. Henao Ardila DF. Extraños nómadas y confinados. Consultoria para los derechos humanos y el desplazamiento. Codhes; 2004 [Documento en internet]. [consultado 2006 N ov 22]. Disponible en: http:/ /www.codhes.org.co

43. D 'Elia Y. Las políticas sociales desde el enfoque de promoción de calidad de vida. Caracas: Instituto Latinoamericano de Investigaciones Sociales/GTZ/ Fundación Escuela de Gerencia Social Ministerio de Planificación y Desarrollo; 2001.

Artigo apresentado em 21/03/2007

Aprovado em 21/03/2007

Versão final apresentada em 13/04/2007 